\title{
SEMINÁRIO VIRTUAL: UMA FORMA DE DIVULGAR CONHECIMENTO CIENTÍFICO PARA O USO ECONÔMICO E SUSTENTÁVEL DA ARAUCÁRIA E ERVA-MATE NA PANDEMIA DE COVID-19
}

\section{WEBINAR: A WAY TO DISSEMINATE SCIENTIFIC KNOWLEDGE FOR THE ECONOMIC AND SUSTAINABLE USE OF BRAZILIAN PINE AND YERBA-MATE IN THE COVID-19 PANDEMIC}

\author{
Crizane Hackbarth* \\ ORCID: https://orcid.org/0000-0002-3298-4185 \\ Allan Guimarães Borçato** \\ ORCID: https://orcid.org/0000-0003-3822-2859 \\ Eliziane Luiza Benedetti*** \\ ORCID: https://orcid.org/0000-0002-4944-3369 \\ Douglas Rodrigues Sauceda**** \\ ORCID: https://orcid.org/0000-0002-1500-5651
}

\section{Resumo}

O objetivo deste artigo é analisar e divulgar os resultados obtidos com a realização de um seminário virtual (webinar) sobre duas importantes espécies nativas: araucária (Araucaria angustifolia) e erva-mate (Ilex paraguariensis). O presente artigo, de caráter descritivo e qualitativo, aborda o evento "Webinário da Araucária e da Erva-mate", que foi organizado por alunos e servidores do Instituto Federal de Santa Catarina (IFSC) Campi São Carlos e Canoinhas. O evento alcançou centenas de participantes de várias regiões do Brasil e também do exterior, que fizeram a inscrição e avaliação por meio de formulários eletrônicos. Como resultados, destacam-se: o alcance da comunidade externa, o entrosamento e contato positivo com a comunidade de forma virtual, e a atuação protagonista dos discentes. A avaliação do evento foi positiva, tanto para os participantes inscritos quanto para os alunos extensionistas, os quais relataram impacto positivo em sua formação.

Palavras-chave: Evento; Palestra; Webinário; Araucaria angustifolia; Ilex paraguariensis.

\begin{abstract}
This paper aims to analyze and publicize the results obtained from a virtual seminar (webinar) about two important native species: Brazilian pine (Araucaria angustifolia) and Yerba mate (Ilex paraguariensis). It is a descriptive and qualitative study about the event "Webinar of Brazilian Pine and Yerba-mate", organized by students and civil servants of the Federal Institute of Santa Catarina (IFSC) - São Carlos and Canoinhas Campus. The event reached hundreds of participants from various regions of Brazil and worldwide, who made the registration and evaluation through electronic forms. As results, the following stand out: the reach of the external community, the rapport and positive contact with the community in a virtual way, and the protagonist role of the students. The event evaluation was positive, both from the registered participants and from the outreach students, who reported the positive impact on their training.
\end{abstract}

Keywords: Event; Lecture; Webinar; Araucaria angustifolia; Ilex paraguariensis.

Data recebimento: $24 / 03 / 2021$

Data de aceite: $03 / 08 / 2021$
* Professora do Instituto Federal de Santa Catarina (IFSC), São Carlos - SC, Brasil. E-mail: crizane.hackbarth@ifsc.edu.br

*** Professor do Instituto Federal de Santa Catarina (IFSC), São Carlos - SC, Brasil. E-mail: allan.borcato@ifsc.edu.br

${ }^{* * *}$ Professora do Instituto Federal de Santa Catarina (IFSC), Canoinhas - SC, Brasil. E-mail: eliziane.benedetti@ifsc.edu.br

**** Técnico em Agropecuária do Instituto Federal de Santa Catarina (IFSC), São Carlos - SC, Brasil. E-mail: douglas.sauceda@ifsc.edu.br 


\section{Introdução}

A contínua evolução da sociedade introduz novas formas de pensar, de se comunicar, de agir, que se incorporam e se tornam hábitos corriqueiros. O advento da internet ocasionou alterações globalizadas no cotidiano, mediadas por sofisticadas e múltiplas tecnologias (PORTO, 2006). A tecnologia que invadiu os espaços de relações também adentrou nas instituições de ensino, pesquisa e extensão.

O cenário mundial vivenciado a partir de 2020, devido à pandemia do novo coronavírus (SARS-CoV-2), intensificou e ressaltou a importância da utilização dessas tecnologias. As instituições de ensino tiveram de se readequar num curto espaço de tempo, tanto para as atividades de ensino quanto às de extensão e pesquisa. Neste cenário, evidenciou-se a crescente oferta e demanda por atividades on-line, com a finalidade de levar informação e conhecimento para os alunos e para a comunidade externa, como as transmissões ao vivo, mais conhecidas como lives e seminários virtuais, também denominados de Webinários.

A realização de seminários virtuais possibilita um maior alcance de público, indo além das barreiras físicas institucionais, temporais e territoriais. Para algumas áreas, é uma forma de sair do meio acadêmico e de chegar diretamente no público alvo. Além disso, o evento torna-se mais acessível e menos oneroso, possibilitando o atendimento de muitas demandas reprimidas por mais informação e capacitação. Neste caso, podemos citar como exemplo o setor ervateiro e a exploração do pinhão, que são atividades comumente realizadas por pequenos e médios agricultores, muitas vezes de forma rudimentar e sem a aplicação de um conhecimento técnico adequado (BENEDETTI et al., 2019). Além dos agricultores, os profissionais relacionados à produção de erva-mate e do pinhão, como viveiristas, silvicultores, técnicos agrícolas e florestais, e extensionistas rurais necessitam e buscam por conhecimento científico para uma produção economicamente viável e ambientalmente sustentável.

A araucária (Araucaria angustifolia) e a erva-mate (Ilex paraguariensis) são duas espécies nativas brasileiras que ocupam áreas especialmente no Sul do Brasil, mas também em parte da Argentina e Paraguai. As espécies ocupam as mesmas áreas e regiões, sendo uma boa opção para se consorciar a produção (HINKA; KLOCK, 2020). A araucária já foi muito explorada para fins madeireiros, o que a colocou com uma espécie criticamente ameaçada de extinção (IUCN, 2013). Porém, ainda hoje desperta o interesse em ser produzida e preservada devido a sua semente, o pinhão. Já a erva-mate é explorada e conhecida há bastante tempo devido à utilização de suas folhas para chás e outras bebidas, sendo bastante conhecido o chimarrão e o tererê.

O pinhão é consumido pela população e por diversos animais silvestres. Já existem algumas técnicas de produção de mudas de araucária voltadas para a produção de pinhão, que foram desenvolvidas por pesquisas de universidades e empresas públicas. Os agricultores e extensionistas carecem de conhecimento sobre a escolha adequada de matrizes e de material vegetativo para ser propagado, pois a araucária apresenta características peculiares que precisam ser levadas em conta na sua propagação (CONSTANTINO; ZANETTE, 2018).

A erva-mate é utilizada como alimento, compondo diversas bebidas, mas também é potencialmente útil na indústria farmacêutica (FERRERA et al., 2016). Apesar de bastante explorada, apresenta alguns entraves na sua produção, que podem ser contornadas com técnicas ade- 
quadas de seleção de material, adubação, propagação de mudas e manejo de poda (WENDLING; SANTIN, 2015).

A necessidade da interação entre o conhecimento gerado pela pesquisa e a sociedade demonstra a importância das atividades de extensão. A extensão tem relevância por ser fonte de aprendizagem e renovação do conhecimento produzido na universidade e empresas de pesquisa. Isto possibilita a geração de novos conhecimentos de forma interdisciplinar, através de suas ações, tendo como objetivo a criação de um elo entre o meio acadêmico e a comunidade externa, representando o compartilhamento de conhecimentos e saberes (TERRA; ZÜGE, 2013).

O seminário virtual "Webinário da Araucária e da Erva-mate" buscou compartilhar com a comunidade externa, por meio das ações de extensão, conhecimento sobre formas de manejo e técnicas de produção das espécies Araucária e Erva-Mate, obtidas em vários trabalhos de pesquisa. Para os alunos extensionistas, foi uma oportunidade de organizar um evento virtual, estabelecendo uma forma de contato à distância, o que lhes possibilitou uma formação abrangente, para além da sala de aula. Tanto o município de Canoinhas quanto São Carlos estão localizados em regiões de Santa Catarina, em que a exploração de erva-mate e da araucária são atividades econômicas de destaque. Desta forma, além de promover o desenvolvimento local, o evento também cumpriu com um papel fundamental para a formação e aprendizado dos estudantes dos dois Campi do Instituto Federal de Santa Catarina - IFSC, que futuramente poderão se deparar com estas espécies em sua atuação profissional.

O objetivo deste artigo é analisar e divulgar os resultados obtidos a partir da realização deste seminário virtual, de forma a incentivar e fornecer subsídios para que mais eventos virtuais ou híbridos sejam realizados futuramente.

\section{Procedimentos Metodológicos}

O seminário virtual intitulado "Webinário da Araucária e da Erva-Mate" foi organizado por alunos do curso técnico em Agropecuária (Campus São Carlos) e do curso de Bacharelado em Agronomia (Campus Canoinhas), totalizando nove discentes extensionistas, além de docentes e técnicos administrativos do IFSC, de ambos os Campi.

$\mathrm{O}$ evento foi composto por cinco palestras com temas relacionados à produção de araucária e de erva-mate. As palestras abordavam conhecimentos técnicos e científicos advindos de pesquisas realizadas com as duas espécies. Os palestrantes eram especialistas de instituições importantes e de referência na área. O público-alvo foi bastante diversificado e contou com estudantes, agricultores, viveiristas, extensionistas, professores, pesquisadores, ervateiras, engenheiros agrônomos e florestais e público em geral interessado pelo tema.

A demanda para realizar um evento nessa temática deu-se por pessoas da comunidade externa, de diversas cidades e estados do país, após a realização de uma palestra virtual sobre a araucária. Extensionistas, viveiricultores e produtores de pinhão e erva-mate entraram em contato via rede social e e-mail, tanto com a instituição quanto com os organizadores, para a realização de novas palestras virtuais sobre o tema araucária e erva-mate. Para a concretização 
do evento, foram realizadas diversas atividades, por todos os membros da comissão organizadora. Os/as alunos/as tiveram papel fundamental e foram protagonistas nesta ação de extensão. Dentre as atividades, a elaboração da arte de divulgação do evento foi feita pelos/as estudantes extensionistas, bem como os formulários de inscrição e de avaliação das palestras. Os/as estudantes organizaram o roteiro do cerimonial e participaram da execução do cerimonial de todas as palestras.

A ação de extensão foi cadastrada por palestra, no Edital PROEX nº 42/2019 - Fluxo Contínuo Projetos ou Cursos - do Instituto Federal de Santa Catarina, tendo como códigos identificadores EV056-2020, EV057-2020, EV064-2020, EV065-2020 e EV066-2020.

A divulgação do evento foi feita por meio das redes sociais oficiais dos dois Campi e também via aplicativo de mensagem instantânea. Para a divulgação do evento, além do folder contendo as principais informações, foram elaboradas algumas curiosidades sobre as duas espécies (Figura 1), visando despertar o interesse do público-alvo e estimular a pesquisa e aprendizagem dos/as estudantes extensionistas sobre o tema a ser abordado. A divulgação da curiosidade era acompanhada de uma ou duas imagens relacionadas e de uso livre, que pudessem chamar a atenção. As curiosidades foram divulgadas em dias alternados, tanto previamente ao evento quanto durante a sua realização. As atividades desenvolvidas pelos/as estudantes extensionistas foram supervisionadas e orientadas pelas professoras coordena-doras da atividade de extensão.

Figura 1 - Algumas curiosidades elaboradas para a divulgação do evento "Webinário da Araucária e da Erva-Mate".
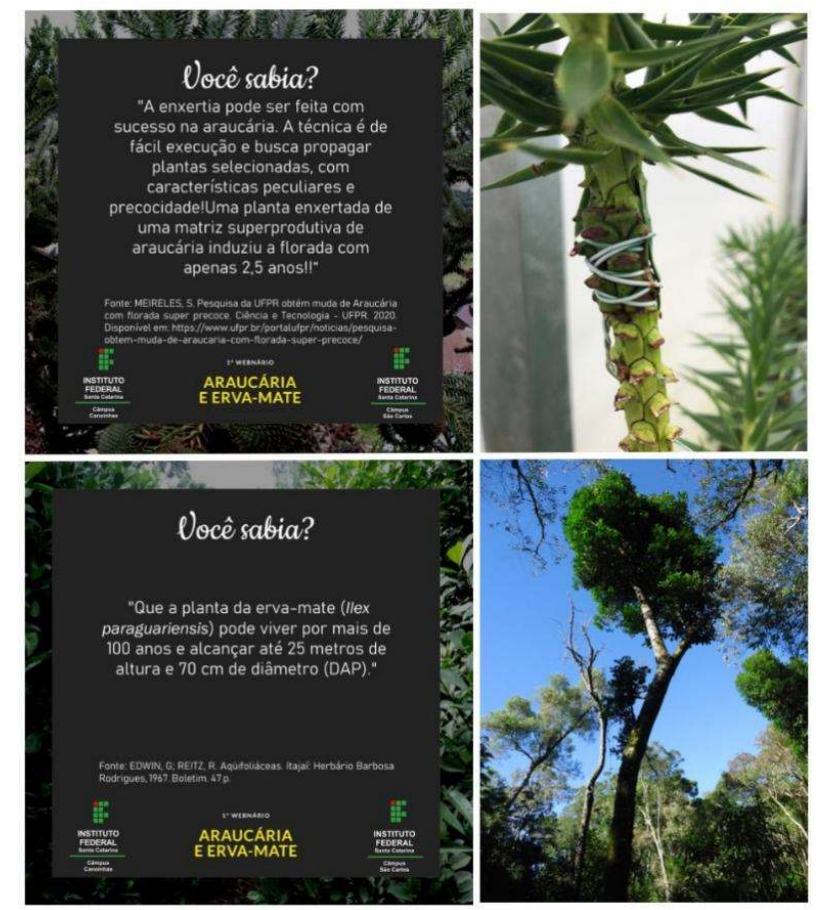

Fonte: Elaborada pelos/as autores/as. 
A inscrição no evento foi feita por meio de formulário eletrônico. Após efetivar a inscrição, os/as participantes foram direcionados/as para um grupo de um aplicativo de mensagens instantâneas, por onde foi feita a comunicação entre a comissão organizadora e os/as mesmos/ as. $\mathrm{O}$ endereço eletrônico para o acesso às palestras foi enviado aos/às participantes inscritos/ as tanto pelo grupo quanto para o e-mail cadastrado na inscrição, previamente, a cada palestra. Além das informações necessárias para o acesso à palestra, foi divulgada, juntamente com o material, uma curiosidade relacionada ao tema (Figura 1).

O seminário virtual foi transmitido pelo YouTube ${ }^{\circledR}$. Para tal, foi criado um canal do evento nesta plataforma. As palestras ocorreram em julho e agosto de 2020, sempre às 19h (GMT 3). Os/as estudantes, além de conduzirem o cerimonial de todas as palestras, também fizeram a transmissão de algumas delas, atividade que também foi compartilhada com os/as servidores/as.

Para cada dia de palestra, uma equipe de apoio foi montada para fazer o cerimonial/ apresentação, esclarecer as dúvidas dos/as participantes, anotar os questionamentos para o/a palestrante, fazer o treinamento prévio com o/a palestrante e enviar as informações para o acesso e formulário de avaliação.

As palestras tiveram duração de cerca de duas horas, incluindo o tempo destinado ao esclarecimento de dúvidas dos/as participantes pelo/a palestrante, e o formulário de avaliação ficava disponível para respostas até às $22 \mathrm{~h}$ do dia de cada palestra.

Após o recebimento das respostas dos formulários de inscrição e avaliação, as informações foram tabuladas, gerando subsídios para a apresentação e discussão dos resultados. A análise e interpretação dessas informações foram realizadas de forma ampla, correlacionando com outros conhecimentos e com a realidade socioeconômica regional de abrangência dos dois Campi promotores do evento.

O formulário de avaliação foi organizado de forma semiestruturada e foi respondido tanto por inscritos/as quanto por não inscritos/as que estavam participando das palestras virtuais. O formulário de avaliação continha questões sobre a motivação que levou o/a participante a assistir às palestras, a forma como o/a participante soube do evento, seu interesse em participar de novos eventos promovidos pelo IFSC, a contribuição do evento para a vida profissional, o desempenho da comissão organizadora, além de uma pergunta de resposta aberta referente a críticas e sugestão de temas para eventos futuros. Para cada palestra, foi elaborado um formulário de avaliação distinto, e as críticas e sugestões auxiliaram a comissão em melhorias do próprio evento.

\section{Resultados e Discussão}

O evento contou com 534 participantes inscritos, de diversos estados do país e de outros países, como Argentina e Paraguai. Além da quantidade de inscritos no evento, outro ponto importante que evidenciou a boa aceitação foi o número de inscritos/as no canal, que ultrapassou 270 inscrições no primeiro mês de sua criação. A quantidade de visualização das palestras ultrapassou as 5 mil (Figura 2). Isto, sem dúvida, é proporcionado pelo modelo de apresen- 
tação virtual, o qual possibilita que os/as participantes possam assistir às apresentações de qualquer lugar e a qualquer tempo.

Uma questão que pode ter favorecido a boa aceitação e acessos às palestras é o fato da ocorrência da pandemia do novo coronavírus, momento em que o seminário virtual foi realizado. Neste período, o distanciamento social, também chamado de isolamento social, foi uma das medidas de controle e prevenção da doença, recomendado pelas autoridades sanitárias em diferentes esferas administrativas (BEZERRA et al., 2020). Com isso, as pessoas buscaram reorganizar as suas rotinas, e eventos virtuais ganharam maior notoriedade.

Figura 2 - Canal do evento "Webinário da Araucária e Erva-Mate" no YouTube ${ }^{\circledR}$ com as palestras transmitidas e a quantidade de visualizações até março de 2021.

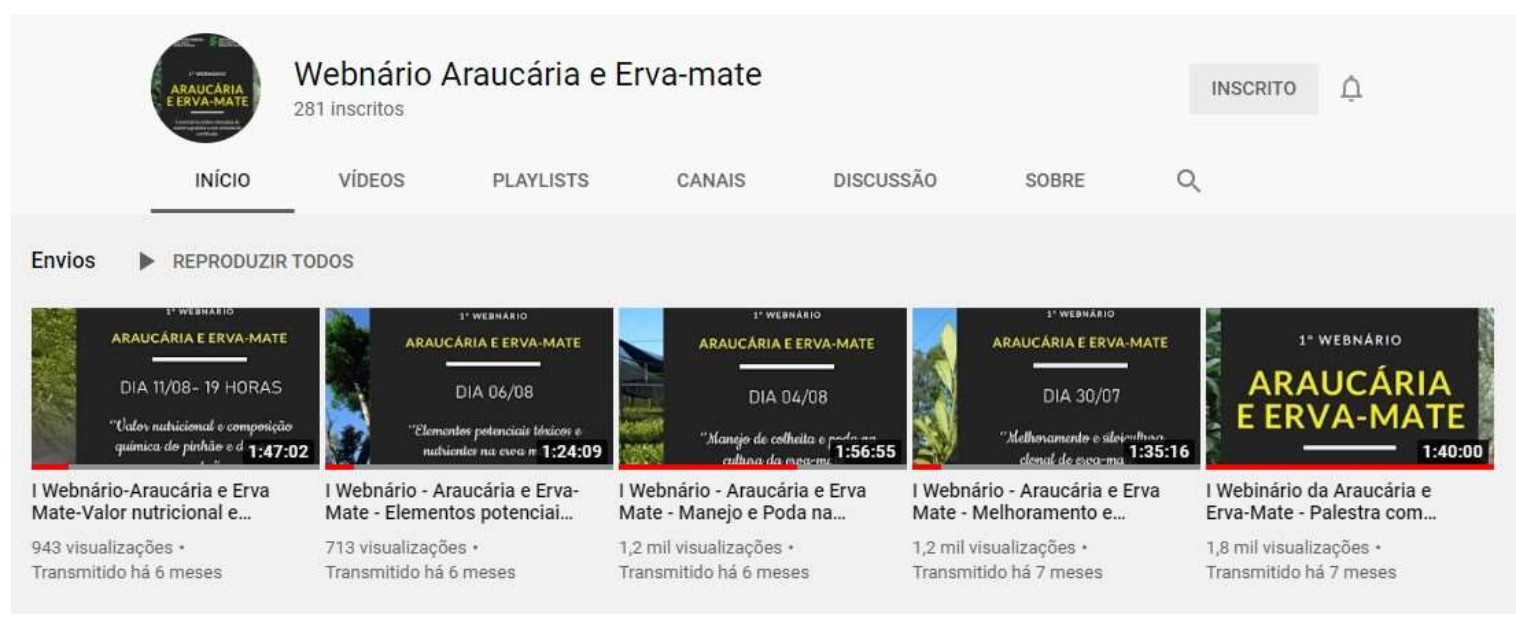

Fonte: Elaborada pelos/as autores/as.

Além disso, percebe-se que as regiões onde a araucária e a erva-mate possuem uma maior ocorrência, como os estados da região Sul do Brasil (Rio Grande do Sul, Paraná e Santa Catarina) e as províncias da Argentina próximas à divisa do Brasil, foram as que contaram com uma maior quantidade de inscritos. No caso dos países vizinhos, 28 pessoas se inscreveram previamente, número superior à quantidade de inscritos/as do estado de São Paulo, por exemplo, que registrou 11 inscritos/as. Isto se deve à importância que as espécies possuem nessas regiões. A localização por estado ou país dos/as participantes inscritos/as está apresentada no Gráfico 1. Para uma melhor representação dos dados, eles foram plotados em escala logarítmica.

A erva-mate possui importância socioeconômica, principalmente no Sul do Brasil e países limítrofes, como Argentina, Uruguai e Paraguai, sendo utilizada na indústria alimentícia para produção de chimarrão, tererê e chá-mate (CUQUEL et al., 1994). Brasil e Argentina produzem mais de $90 \%$ da erva-mate no mundo (CENTENARO et al., 2020). No Brasil, a participação foi intensa nos três estados do Sul, com $87 \%$ dos/as inscritos/as, sendo a maior parte dos/as participantes do estado do Paraná, seguido por Santa Catarina e Rio Grande do Sul. 
O estado do Paraná é tido como o maior produtor nacional de pinhão, mas é seguido de perto por Santa Catarina. Por dez anos seguidos, de 2008 a 2018, o Paraná ocupou a primeira posição na produção de pinhão, chegando a ser responsável por $57 \%$ do total produzido, mas, em 2018, Santa Catarina passou a ocupar a primeira posição, assim como era até 2007. Em 2018, a produção nos dois estados foi muito próxima (35\% no Paraná e $38 \%$ em Santa Catarina) (CONAB, 2020). Vale ressaltar que a comercialização do pinhão por vias informais, como a que é feita em beira de estradas, é bastante frequente na região, especialmente nos meses de colheita da semente.

Gráfico 1 - Local (estado e/ou país) dos participantes inscritos no seminário virtual "Webinário da Araucária e da Erva-Mate".

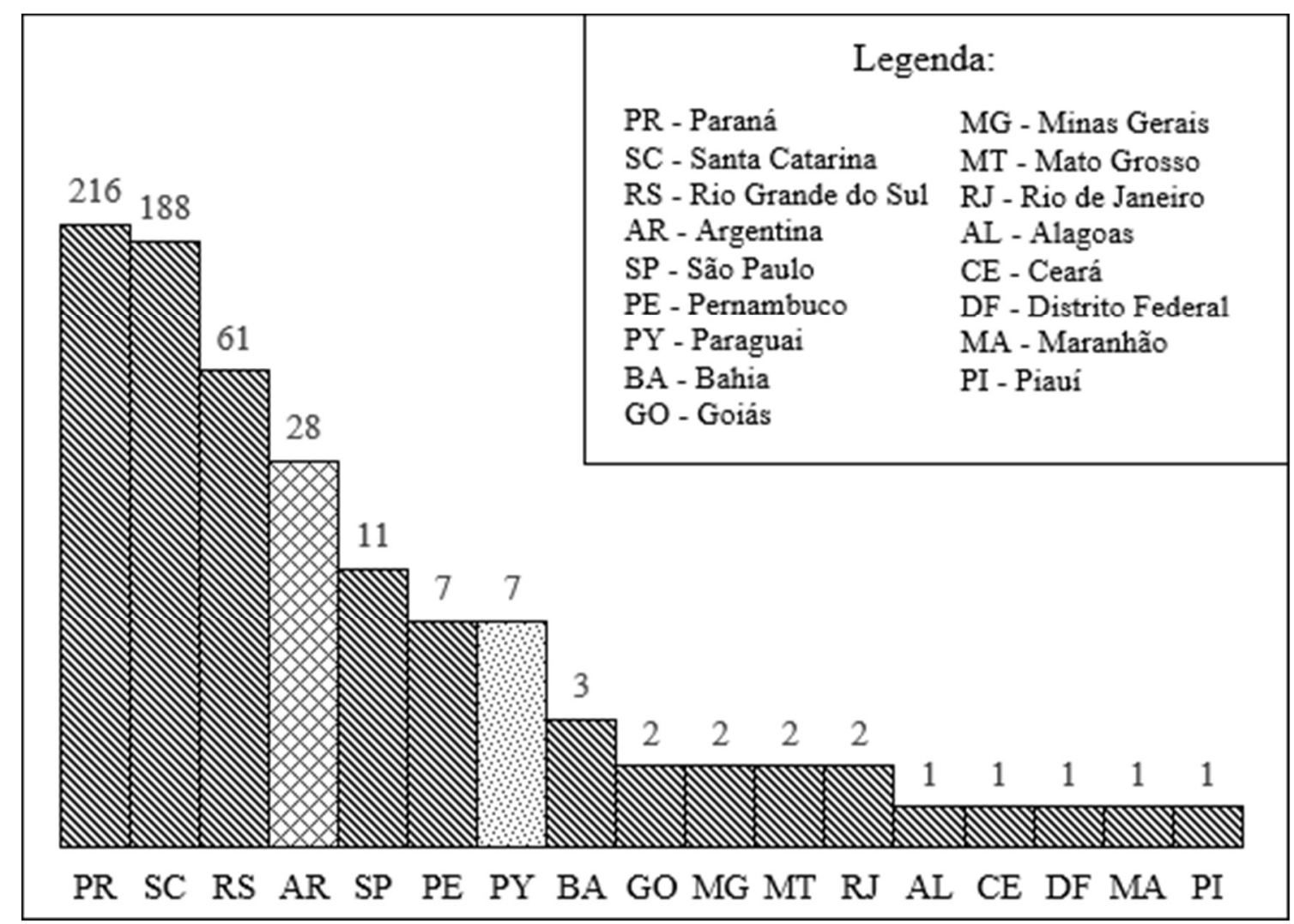

Fonte: Elaborado pelos/as autores/as.

O formulário de avaliação das cinco palestras do evento contou com 1.417 respostas e, em algumas das perguntas, os/as participantes tinham a opção de escolher mais de uma alternativa. $\mathrm{O}$ formato virtual para o evento foi, sem dúvida, um ponto-chave para a participação de grande público de fora da área de abrangência do IFSC, incluindo o exterior do país. Para $65,5 \%$ dos/as respondentes, a acessibilidade virtual foi um dos aspectos mais úteis das palestras, e para $58,3 \%$ o fato de ser um evento virtual foi o que chamou a atenção para participar (Gráfico 2). 
Percebe-se que o formato virtual é assertivo com o público interessado nestes temas, ou seja, muitos dos/as participantes que procuraram o evento o fizeram porque estavam realmente interessados/as nos assuntos abordados. Isto fica evidente quando $96,5 \% \mathrm{dos} /$ as participantes responderam que o conteúdo abordado foi um dos aspectos mais úteis das palestras, e 71,4\% responderam que a possibilidade de aumentar seus conhecimentos foi um dos fatores que chamaram a atenção para participar do evento (Gráfico 2). Nessas perguntas, o/a participante podia escolher mais de uma alternativa.

Gráfico 2 - Aspectos mais úteis das palestras apontados pelos participantes (A). O que chamou a atenção para participar do evento (B).

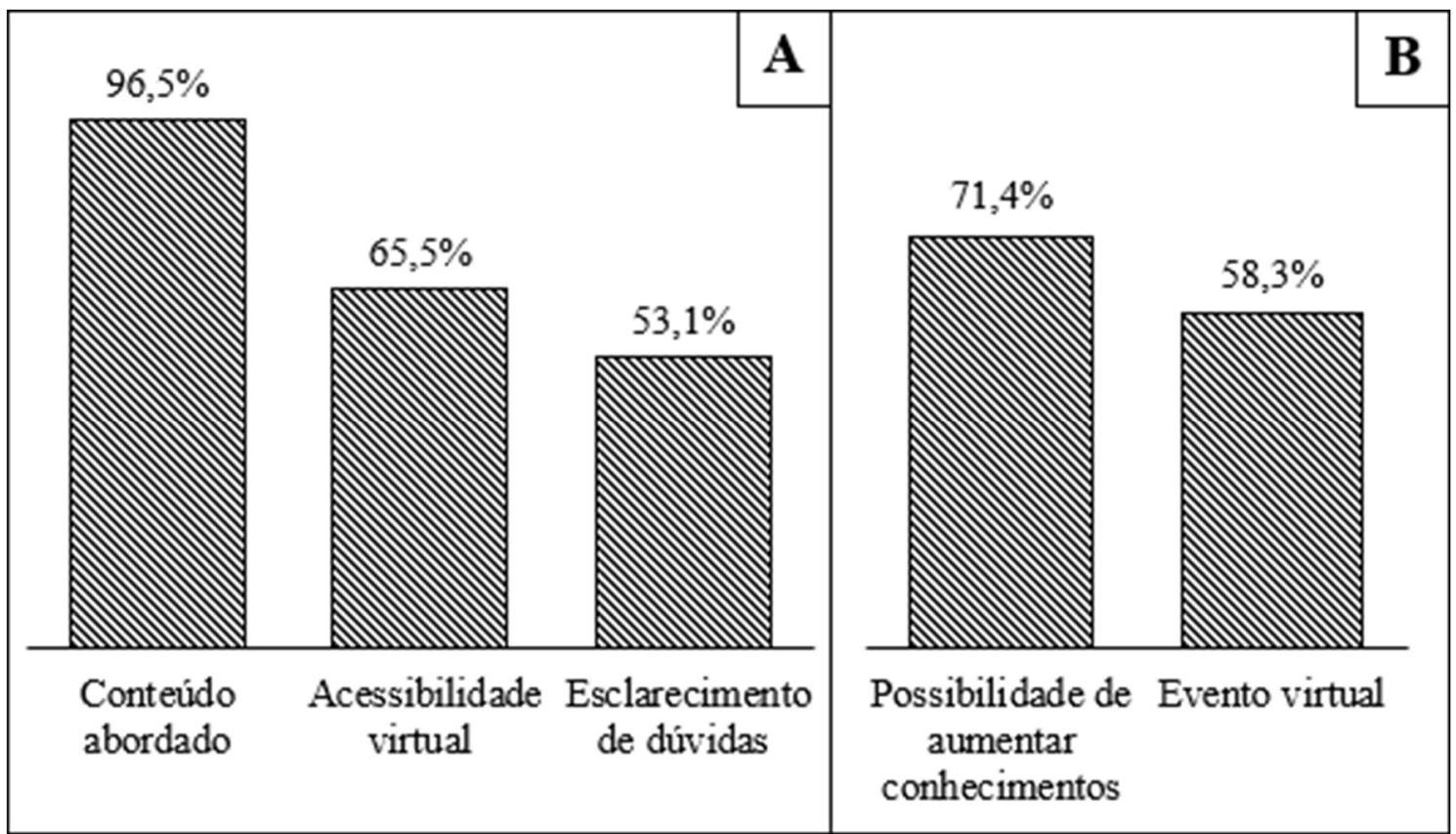

Fonte: Elaborado pelos/as autores/as.

Eventos presenciais proporcionam um contato mais íntimo e envolvente, "olho no olho", o que é mais difícil de ser reproduzido em formatos virtuais. Ambos apresentam vantagens e desvantagens. Contudo, o momento crítico vivenciado pelo medo da contaminação pelo Sars-Cov-2 e a necessidade de distanciamento social potencializaram as interações remotas. As telas passaram a ter um espaço ainda maior e foram uma das formas mais seguras de intercâmbio de informações, experiências e contato.

A forma como os/as participantes tiveram conhecimento sobre o evento é apresentada no Gráfico 3, e para a pergunta era possível o/a participante responder mais de uma alternativa. Para a grande maioria dos/as inscritos/as, a divulgação feita por aplicativos de mensagens e redes sociais foi majoritária e se destacou perante as demais formas de divulgação. O aplicativo de mensagem WhatsApp ${ }^{\circledR}$ foi a mídia social que proporcionou um maior alcance de 
participantes inscritos/as (71\%), enquanto as divulgações feitas pelo Facebook ${ }^{\circledR}$ e Instagram $^{\circledR}$ alcançaram $37 \%$ dos/as participantes. Isto evidencia a força que estes instrumentos exercem sobre as pessoas atualmente, já que muitas os utilizam como uma maneira de obter informação, inclusive capacitações técnicas.

O uso de aplicativos de mensagens é, por vezes, mal-visto quando mal-empregado, mas a experiência do uso do WhatsApp ${ }^{\circledR}$, aplicativo muito conhecido, como um recurso para educação em saúde mostrou-se bem-sucedida (PAULINO et al., 2018). A utilização das mídias sociais Facebook ${ }^{\circledR}$ e WhatsApp ${ }^{\circledR}$ em atividades de formação e extensão também foi satisfatória. Kockhann et al. (2018) relatam que:

[...] as mídias, como ferramentas pedagógicas, podem vir a ser um grande contributo para o bom andamento do projeto, auxiliando na comunicação, na troca de experiência, na aprendizagem e produção à distância e os motivando a realizar atividades diferenciadas a serem publicadas, superando as barreiras do tempo e espaço. (KOCKHANN et al., 2018, p. 2).

Gráfico 3 - Como o participante soube da ocorrência do evento "Webinário da Araucária e da Erva-Mate".

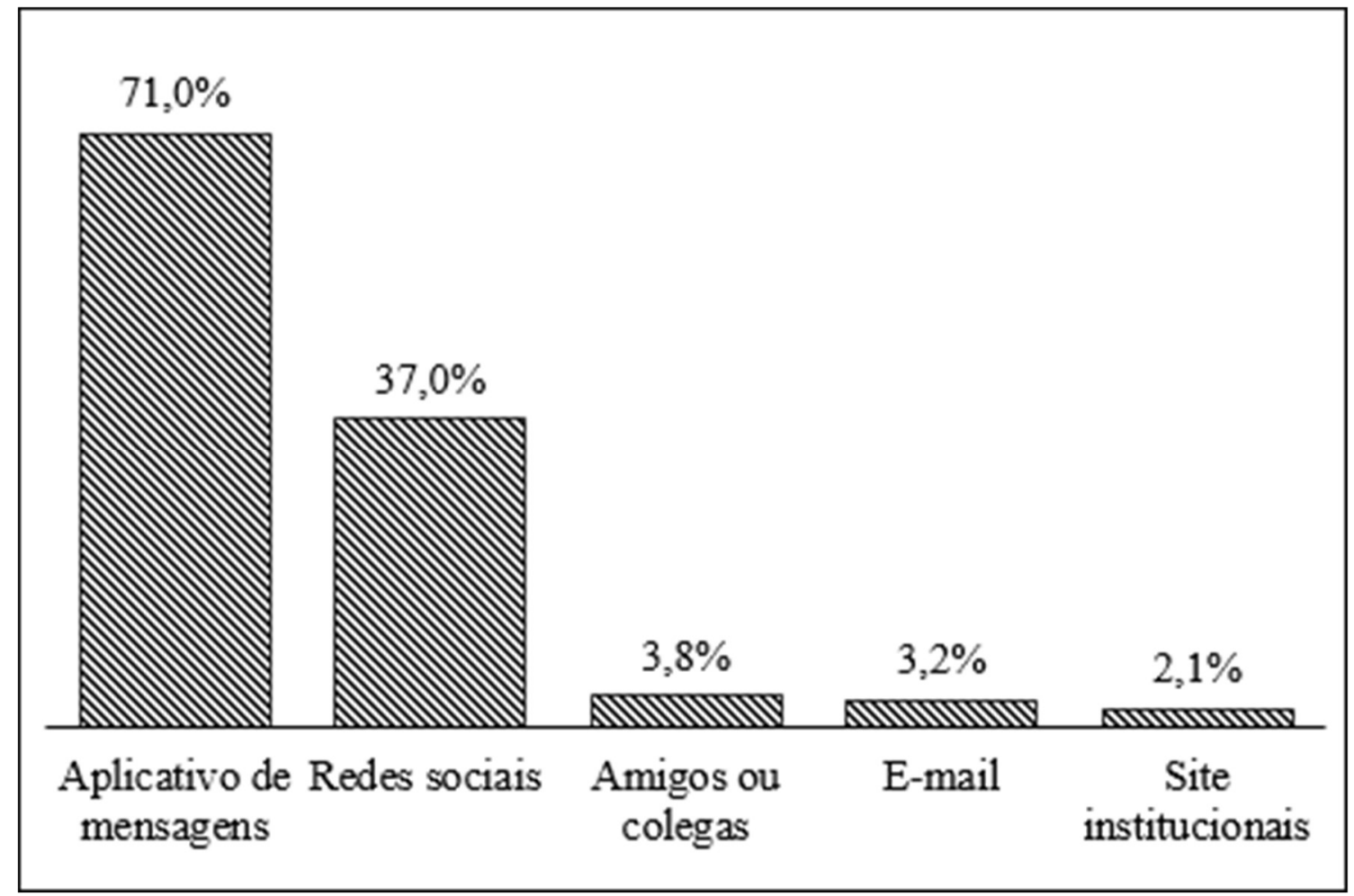

Fonte: Elaborado pelos/as autores/as. 
A avaliação geral do evento é apresentada no Gráfico 4. O evento como um todo apresentou um alto índice de aceitação, pois mais de $98 \%$ das pessoas que responderam ao questionário de avaliação indicaram que o conteúdo abordado foi satisfatório ou muito satisfatório. Além disso, quando perguntadas se participariam de outro evento virtual promovido pelo IFSC, cerca de $92 \%$ das pessoas afirmaram que participariam novamente. Estes dados demonstram o sucesso alcançado pelo evento, mesmo diante de um público heterogêneo, formado por alunos/ as, docentes, pesquisadores/as, extensionistas, agricultores/as etc. O nível de especialização e conhecimento dos/as palestrantes foi um dos pontos elogiados por diversos respondentes, bem como a boa organização do evento.

Atualmente, é possível observar eventos virtuais sendo organizados em plataformas específicas, sofisticadas estruturas pensadas para eventos híbridos, com milhares de participantes e estruturas mais simples como lives no Instagram ${ }^{\circledR}$, por exemplo. A forma de organização e interação é diferente nos três casos. A boa avaliação obtida no presente evento se deu devido à interação que a comissão organizadora teve com os/as participantes inscritos/as. Apesar de distanciados/as por uma tela, o contato foi quase que diário. As dúvidas dos/as participantes eram respondidas diariamente pela comissão, via e-mail ou aplicativo, e os envios das curiosidades sobre as espécies proporcionaram um canal de interação, já que alguns/as inscritos/as compartilhavam os envios em suas próprias fotos e mensagens.

Gráfico 4 - Avaliação do conteúdo abordado nas palestras (A). Participação em eventos futuros realizados pelo IFSC (B).

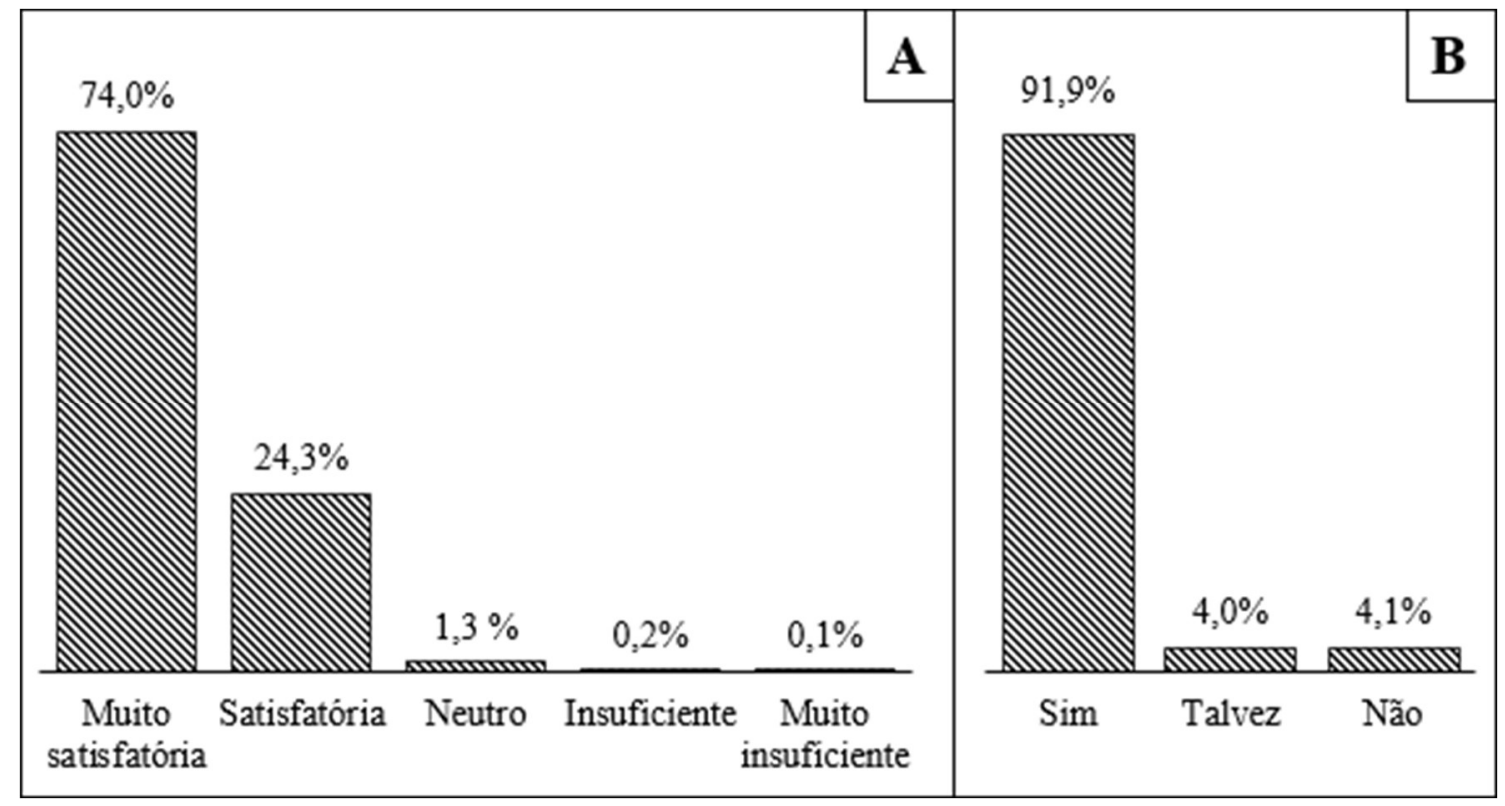

Fonte: Elaborado pelos/as autores/as. 
Este contato, mesmo que remoto, precisa ser garantido para que o/a participante se sinta acolhido/a e perceba que, do outro lado da tela, também há uma pessoa assim como ele/a. Essa interação cria um senso de comunidade. Ao final de cada palestra, todas as dúvidas eram respondidas pelos/as palestrantes, o/a participante escrevia no chat e a pergunta era lida pelo/a moderador/a. Esse intercâmbio foi riquíssimo e representou um dos pontos fortes do evento.

Do total de participantes inscritos/as no evento, 9\% eram discentes do IFSC. Portanto, a grande maioria fazia parte da comunidade externa. Isto demonstra que eventos como este possuem um bom potencial para atrair público externo e também divulgar ações que são desenvolvidas pela instituição. Além de alunos/as participando como ouvintes, o que é uma maneira de ampliar o aprendizado deles/as sobre assuntos que, normalmente, não são vistos em sala de aula, o evento contou com 9 estudantes envolvidos/as diretamente na organização. Para estes/as alunos/as extensionistas, participar da organização impactou na sua formação, por proporcionar aprendizados diversos, interação com pessoas de Campi distintos e a possibilidade de vivenciar o trabalho em equipe. Os/as alunos/as extensionistas relataram que a interação com a comunidade externa também foi impactante na formação. Além disso, o evento proporcionou experiências que aumentaram a autoconfiança dos/as alunos/as para se posicionar diante do público.

Quando questionados/as sobre qual foi a atividade ou experiência mais impactante para a sua formação, as respostas foram diversas, tais como: trabalho em equipe, organização do tempo e das atividades a serem executadas, superação da timidez, interação com pessoas de lugares diferentes e ampliação do conhecimento. A avaliação dos/as alunos/as confirma que, por vezes, a formação ampla e externa à sala de aula proporcionada por diversas ações de extensão é uma aliada para os/as alunos/as se sentirem mais preparados/as para atuar frente à comunidade. Todos/as os/as alunos/as responderam que gostariam de participar de outras atividades de extensão e todos/as responderam que se sentem preparados/as para atuar com a comunidade externa.

\section{Conclusões}

O formato usado para a realização do evento possibilitou alcance e compartilhamento de conhecimento técnico e científico sobre a araucária e erva-mate a um grande número de participantes com formação e atuação diversificadas, de diversas regiões do país e também de alguns países vizinhos

Os eventos virtuais não substituem o contato e a interação gerados em eventos presenciais; entretanto, quando bem conduzidos, podem gerar um bom envolvimento entre organizadores/ as, palestrantes e participantes.

A participação dos/as alunos/as na organização do evento foi muito importante para a sua realização, além de ser uma experiência única na formação diferenciada deles/as. 


\section{Referências}

BENEDETTI, E.L.; SANTIN, D.; STASKOVIAK, A.P.; NOVAK, C.F.; JANSEN, T.A.L.; MORAIS, B.C. Adubação orgânica estimula o crescimento de erva-mate e de araucária a campo. Revista Eletrônica Técnico-Científica do IFSC, v.2, n.9, 2019. Disponível em: https://cutt.ly/yfjPVcu. Acesso em: 29 ago. 2020.

BEZERRA, A.C.V.; SILVA, C.E.M.; SOARES, F.R.G.; SILVA, J.A.M. Fatores associados ao comportamento da população durante o isolamento social na pandemia de COVID19. Ciência \& Saúde Coletiva, v.25, p. 2411-2421, 2020. Disponível em: https://cutt.ly/WfI5z4v. Acesso em: 28 ago. 2020.

CENTENARO, M.; SATTLER, S.A.; SILVEIRA, C.V.; OLIVEIRA, H.C.C.R. Evolução da produção e tecnologias no cultivo de erva-mate: análise entre Brasil e Argentina. Revista Profanações, ano 7, n. esp., p. 90-107, 2020. Disponível em: https://cutt.ly/zlXNcXu Acesso em: 01 mar. 2021.

COMPANHIA NACIONAL DE ABASTECIMENTO (CONAB). Boletim Sociobiodiversidade, v.4, n.2, p. 1-39, abr./maio/jun. 2020. Disponível em: https://cutt.ly/RfjPCWt. Acesso em: 30 ago. 2020.

CONSTANTINO, V.; ZANETTE, F. Enxertia de propágulos trunciformes nos ramos de Araucaria angustifolia e multiplicação de matrizes. Ciência Florestal, v.28, n.2, p. 845853, 2018. Disponível em: https://cutt.ly/lfI5nT5 Acesso em: 30 ago. 2020.

CUQUEL, F.L.; CARVALHO, M.L.M.; CHAMMA, H.M.C.P. Avaliação de métodos de estratificação para a quebra de dormência de sementes de erva-mate. Scientia Agricola, Piracicaba, v.5, n.3, p. 415-421, 1994. Disponível em: https://cutt.ly/efi5h01 Acesso em: 26 ago. 2020 .

FERRERA, T.S.; HELDWEIN, A.B.; DOS SANTOS, C.O.; SOMAVILLA, J.C.; SAUTTER, C.K. Substâncias fenólicas, flavonoides e capacidade antioxidante em erveiras sob diferentes coberturas do solo e sombreamentos. Revista Brasileira de Plantas Medicinais, v.18, n.2, p. 588-596, 2016. Disponível em: https://cutt.ly/mfI5Q19. Acesso em: 25 ago. 2020.

HINKA, I.; KLOCK, M.C.L. Agrofloresta: manejo da erva-mate consorciada com a Floresta de Araucária. Monografia (Especialização em Educação do Campo) - Universidade Federal do Paraná - Setor Litoral, Matinhos, 2020. 17 p. Disponível em: https://cutt.ly/lfI5EhD. Acesso em: 29 ago. 2020.

INTERNATIONAL UNION FOR CONSERVATION OF NATURE (IUCN). Araucaria angustifolia. The IUCN 2013's Red List of Threatened Species: e.T32975A2829141, 2013. Disponível em: https://cutt.ly/oft6Gtl Acesso em: 29 ago. 2020. 
KOCHHANN, A.; AMORIM, M.C.S.; MARQUES, M.H.; RIBEIRO, N.; FERNANDES, T.O. As mídias como ferramentas pedagógicas: uma experiência em um projeto de extensão. In: COLÓQUIO ESTADUAL DE PESQUISA MULTIDISCIPLINAR, 3. \& CONGRESSO NACIONAL DE PESQUISA MULTIDISCIPLINAR, 2., 2018, Mineiros. Anais eletrônicos... Mineiros: Pesquisa Unifimes, 2018. Disponível em: https://cutt.ly/51CajGD Acesso em: 01 mar. 2021.

PAULINO, D.B.; MARTINS, C.C.A.; RAIMONDI, G.A.; HATTORI, W.T. WhatsApp ${ }^{\circledR}$ como Recurso para a Educação em Saúde: Contextualizando Teoria e Prática em um Novo Cenário de Ensino-Aprendizagem. Revista Brasileira de Educação Médica, v.42, n.1, p. 166-178, 2018. Disponível em: https://cutt.ly/bfI5RzY. Acesso em: 30 ago. 2020.

PORTO, T.M.E. As tecnologias de comunicação e informação na escola: relações possíveis... relações construídas. Revista Brasileira de Educação, v.11, n.31, p. 43-57, 2006. Disponível em: https://cutt.ly/TfI5TQ1. Acesso em: 30 ago. 2020.

TERRA, S.T.B.; ZÜGE, D.P.P.O. Floricultura: a produção de flores como uma nova alternativa de emprego e renda para a comunidade de Bagé-RS. Revista Conexão UEPG, v.9, n.2, p. 342-353, 2013. Disponível em: https://cutt.ly/ofI5Y38. Acesso em: 30 ago. 2020.

WENDLING, I.; SANTIN, D. Propagação e nutrição de erva-mate. Brasília, DF: Embrapa, 2015. 